\title{
GOVERNANÇA AMBIENTAL NA GESTÃO PÚBLICA PARA O ENFRENTAMENTO ÀS MUDANÇAS CLIMÁTICAS: DESAFIOS ENFRENTADOS PELOS PEQUENOS MUNICÍPIOS
}

Gabriel Pires de ARAÚJO²

RESUMO: O atual cenário de emergência climática demanda respostas por parte dos governos locais, uma vez que é na escala local onde a emergência se materializa. Entretanto, é preciso compreender as características das diferentes conformaçóes territoriais, inclusive no que concerne às dificuldades para a adaptação e a importância da Governança Ambiental como norteador para o enfrentamento à problemática. Nesse contexto, o presente artigo apresenta o estudo de caso que busca analisar a capacidade institucional de pequenos municípios que integram a região do Vale Histórico Paulista para o enfrentamento as Mudanças Climáticas, considerando que os pequenos municípios possuem dificuldades inerentes a essa escala e demandam atenção em estudos acadêmicos. O estudo se baseia numa análise de conteúdo da normativa urbana dos municípios e na realização de entrevistas com os gestores públicos. Os resultados preliminares indicam que ações para o enfrentamento à problemática estão presentes de forma marginal na normativa urbana e que, embora os gestores públicos reconheçam a importância da participação social e da governança, ela não ocorre de forma efetiva, indicando a importância de reflexão sobre essa problemática no escopo de pequenos municípios.

PALAVRAS-CHAVE: adaptação; mudanças climáticas; governança ambiental; pequenas cidades; gestão local.

\footnotetext{
1 Agradeço a CAPES pelo financiamento da pesquisa de nível de mestrado cuja qual este artigo resultou. Este texto é também proveniente de pesquisas realizadas no âmbito do projeto temático "Governança ambiental na Macrometrópole Paulista, face à variabilidade climática" (processo no 15/03804-9), financiado pela FAPESP e vinculado ao Programa FAPESP de Pesquisa sobre Mudanças Climáticas Globais.

2 Universidade de São Paulo (USP), Programa de Pós Graduação em Ciência Ambiental do Instituto de Energia e Ambiente, São Paulo - SP - Brasil. Mestrando em Ciência Ambiental. ORCID: https://orcid.org/0000-0002-25154706.gabrielparaujo.ga@gmail.com.
} 


\title{
ENVIRONMENTAL GOVERNANCE IN PUBLIC MANAGEMENT \\ TO ADDRESS CLIMATE CHANGE: CHALLENGES OF SMALL MUNICIPALITIES FROM A CASE STUDY
}

\begin{abstract}
The current climate emergency scenario demands responses from local governments as it is at the local scale where it materializes the effects of climate change. However, it is necessary to understand the differents characteristics of the territorial conformations, including with regard to the difficulties of adaptation and the importance of Environmental Governance as a guide for facing the problem. In this context, this article presents the case study that seeks to analyze the institutional capacity of the small municipalities that integrate the Historic Valley region of São Paulo to face Climate Change, considering that small municipalities have difficulties inherent to this scale that demand attention in academic studies. The study is based on a content analysis of the urban regulations of the municipalities and on the conduct of interviews with public managers. Preliminary results indicate that actions to tackle the problem are marginally present in urban regulation and that, although public managers recognize the importance of social participation and governance, it does not occur effectively, indicating the importance of reflection on the theme in small municipalities.
\end{abstract}

KEYWORDS: adaptation; climate change; environmental governance; small town; local management.

\section{Introdução}

O processo de mudanças climáticas é o principal desafio da humanidade no século XXI (GIDDENS, 2010). De causa predominantemente antrópica, o processo é caracterizado principalmente pelo aumento médio da temperatura do planeta e tem como resultado uma maior variabilidade climática que resulta em consequências negativas tanto ecológicas quanto socioeconômicas (GIDDENS, 2010; IPCC, 2014).

$\mathrm{O}$ atual modelo de produção e consumo hegemonicamente baseado na concepção capitalista neoliberal de exploração e seu consequente alto nível de emissões de Gases do Efeito Estufa (GEE) não convergem com o Acordo de Paris. Aprovado em 12 de Dezembro de 2015, o acordo tem como objetivo manter o aumento médio da temperatura global em menos de $2^{\circ} \mathrm{C}$ até o final do século XXI e foi ratificado por 153 países até Julho de 2017 (ANDERSON, 
2015; VICTOR et al., 2017). Além disso, não se apresenta no horizonte de curto prazo uma tendência clara de mudanças consistentes no modelo de desenvolvimento hegemônico, posto que nenhum dos grandes países industrializados apresenta, até o momento, condiçóes de cumprir as promessas acerca do controle de emissão de GEE do acordo (KÄSSMAYER; FRAXE NETO, 2016; VICTOR et al., 2017).

Conforme Steffen et al. (2018), a depender das atitudes sociais e tecnológicas adotadas nas próximas uma ou duas décadas, pode-se fazer com que o Sistema Terra apresente condiçóes inóspitas para as atuais sociedades humanas e para muitas outras espécies contemporâneas.

Essa aparente incapacidade de fazer frente à emergência climática por meio das atuais medidas de mitigação de emissóes, atrelada à crise socioambiental que se caracteriza, dentre outros aspectos, pela ultrapassagem do limite planetário referente às mudanças climáticas, complexificam ainda mais o cenário (ROCKSTROM et al., 2009; STEFFEN et al., 2015, 2018). Destaca-se que essa ultrapassagem aumenta a relevância da adaptação às mudanças climáticas, uma vez que, de acordo com Steffen et al. $(2015,2018)$, a complexa dinâmica climática pode fazer com que o aumento da temperatura decorrente da emissão de GEE continue mesmo que eventualmente se reduzam as emissóes.

Dentre os efeitos negativos das mudanças do clima, este texto trabalha com mais afinco os que se referem ao aumento na frequência e intensidade de Eventos Hidrometeorológicos Extremos (EHEs), que desencadeiam a ocorrência de desastres como escorregamentos, inundaçóes e enchentes (LANDA; MAGAÑA; NERI, 2008; NUNES, 2009a; FLORES; GAUDIANO, 2014; LONDE et al., 2014).

Um desastre só é definido como tal quando determinados eventos incidem sobre sociedades humanas ou impactam suas atividades e valores. Ou seja: se ocorrem em áreas remotas e não afeta populações, é um fenômeno natural. Já se afeta agrupamentos humanos, causando desabrigados, feridos, mortos e prejuízos econômicos, são desastres que, a depender de sua extensão, são classificados como catastróficos (NUNES, 2009a).

Portanto, a ocorrência de desastres relacionados às MCG como os EHEs estão diretamente relacionados com a vulnerabilidade das populaçôes atingidas, sendo questóes como a ocupação desigual do espaço pela sociedade, que delega as áreas com maiores riscos para as populaçóes mais pobres, um dos principais fatores desencadeadores de desastres em um contexto de injustiça climática, um problema importante a ser tratado na perspectiva da adaptação (NUNES, 2009b; TORRES et al., 2020). 
A adaptação às mudanças climáticas se refere "[...] aos ajustes nos padróes humanos de assentamento, de produção, de circulação, de construção, entre outros, gerando maior congruência com as exigências de um clima alterado in situ, nos níveis locais, regionais e globais" (LAVELL, 2010, p. 14). Além de ser um processo contínuo que deve ser apreendido pela gestão pública local (BARBI, 2014), a adaptação deve considerar as características de cada país, posto que a gravidade dos efeitos das mudanças climáticas irá variar de acordo com a localização geográfica dos países e de sua capacidade de resposta, sendo os países em desenvolvimento do espaço geográfico do Sul Global, localizado nos trópicos, os que mais sofrerão (BATHIANY et al., 2018).

Uma das características do Brasil, um dos países do Sul Global localizado nos trópicos, é a sua conformação espacial, que é majoritariamente de pequenos municípios $-77 \%$ do total de municípios possui menos de 20 mil habitantes (FERNANDES, 2018). Considerando que os principais efeitos negativos das mudanças climáticas serão sentidos na escala local, ou seja, nos municípios (que é em geral onde se expressa a escala local), há um papel primordial no empreendimento de açóes adaptativas por parte dos mesmos (MARTINS; FERREIRA, 2011). Assim, o contexto brasileiro exige que se detenha o olhar sobre os pequenos municípios, considerando-se suas especificidades para a adaptação às mudanças climáticas.

São com esses entendimentos que está sendo realizado, no escopo de uma pesquisa de dissertação de mestrado em andamento, um estudo de caso dos pequenos municípios da região do Vale Histórico Paulista (VHP), mais especificamente Arapeí, Areias e São José do Barreiro, no Estado de São Paulo. Pretende-se com este estudo, analisar a capacidade institucional de municípios que integram a regiáo do VHP para o enfrentamento aos efeitos decorrentes das Mudanças Climáticas Globais (MCG) diante dos cenários já identificados para a região, com especial atenção à resiliência aos EHEs.

O estudo de caso trabalha com uma metodologia interpretativa, que busca compreender a realidade por meio dos sentidos que os indivíduos atribuem às suas experiências (YIN, 2005). Atrelado ao estudo de caso, uma pesquisa de caráter exploratória e qualitativa (GIL, 2002) está sendo feita, com o intuito de embasar o levantamento bibliográfico que se relaciona com o objeto de estudo: Mudanças Climáticas Globais, Adaptação, Escala Local, Governança Ambiental, Organização Institucional e o próprio Vale Histórico Paulista.

Paralelo a isso, foi analisada a normativa urbana das localidades com um olhar particular para os Planos Diretores e os Planos de Saneamento Básico dos municípios. Esta análise pode vir a indicar se há ou náo nos dispositivos legais 
açóes adequadas e condizentes para a adaptação a um cenário de mudanças climáticas. Para tal, foi aplicada a análise de conteúdo, conforme Bardin (1977), com a organização das informaçôes presentes nesses dispositivos, decodificando-as de forma a verificar como as mesmas se apresentam e em que medida podem vir a contribuir para o fortalecimento institucional dos municípios para a adaptação.

Foram realizadas entrevistas semiestruturadas com os gestores públicos municipais, com o intuito de se compreender como se dá a apreensão da questâo climática no âmbito local tendo em vista a necessidade de açôes adaptativas. Combinando perguntas abertas e fechadas, se recorreu a este tipo de entrevista para delimitar o volume das informaçóes e direcionar a entrevista para a temática investigada (BONI; QUARESMA, 2005).

A primeira seção trata sobre os EHEs e a importância da ação na escala local para fazer frente aos mesmos. Já a segunda seção deste artigo apresenta o conceito de governança que norteia a reflexão acerca do objeto de estudo: o conceito de governança ambiental que, como será abordado, possui a capacidade de contribuir para a adoção de medidas adaptativas aos efeitos negativos das mudanças climáticas, inclusive quando em conjunto com a concepção de governança multinível no contexto de pequenos municípios e na sua relação com outras conformações territoriais. Na terceira seção, são apresentados os municípios de Arapeí, Areias e São José do Barreiro e suas principais características socioeconômicas, que evidenciam suas vulnerabilidades. Também são apresentados alguns dos resultados parciais encontrados no contexto da pesquisa de mestrado em andamento acerca da capacidade institucional dos municípios para o enfrentamento às mudanças climáticas, inclusive no que concerne à percepção dos gestores públicos.

\section{Eventos Hidrometeorológicos Extremos decorrentes das Mudanças Climáticas e a importância da Gestão Local para a Adaptação}

As MCG terão efeitos complexos e diversificados, englobando efeitos deletérios na biodiversidade, efeitos negativos na saúde humana por conta do aumento médio da temperatura global, na maior ocorrência de doenças - em especial as transmitidas por vetores - e alteraçóes nos padróes de evaporação e precipitação (NETO, 2010).

No escopo desse artigo, o foco se dá na alteração dos padróes de precipitação, que leva à ocorrência de EHEs, cuja intensidade e frequência tendem a aumentar com o processo de mudanças climáticas (VARGAS, 2013). Os eventos 
hidrometeorológicos extremos desencadeiam a ocorrência de desastres como escorregamentos, inundaçóes, colapso de solos e secas (LANDA; MAGAÑA; NERI, 2008; NUNES, 2009a; FLORES; GAUDIANO, 2014; LONDE et al., 2014).

A ocorrência desses desastres se dá majoritariamente na escala local ou regional (NOGUEIRA; OLIVEIRA; CANIL, 2014), o que demonstra a importância da gestão das localidades como um todo se preparar por meio da perspectiva da adaptação para a ocorrência cada vez mais frequente desses eventos. Além disso, é também na escala local onde fica mais evidente as dificuldades do Estado em prover infraestrutura básica e equipamentos públicos para o enfrentamento dos desastres (MARTINS; FERREIRA, 2011).

A provisão de infraestrutura e equipamentos públicos para a adaptação aos efeitos negativos das mudanças climáticas pressupóe uma prática contínua de açôes cujos resultados se tornam visíveis no médio e longo prazo (BARBI, 2014). Essa prática é muitas vezes relegada pela gestão pública por opçóes políticas de priorizaçáo de temáticas que se refletem em obras de curto prazo e se traduzem em ganhos políticos eleitorais.

Além disso, há outras barreiras que em conjunto também acabam por limitar a formulação e o desenvolvimento de medidas importantes no contexto local. De acordo com Martins e Ferreira (2010), tais barreiras são:

[...] baixa compreensão dos impactos das mudanças climáticas e como essas alteraçóes podem afetar a vida na cidade; grande incerteza sobre a extensão dos impactos que dificulta a tomada de decisão e a definição de prioridades por parte de políticos e autoridades locais; tendência a olhar custos no curto prazo uma vez que muitas opçóes exigem grandes investimentos iniciais; baixa tradição de planejamento de longo prazo por parte do setor público no nível local; dificuldade em comprometer líderes políticos para açóes de longo prazo, uma vez que impera a lógica eleitoral, de mandatos curtos e eles são chamados a responder por problemas urgentes, de curto prazo; problemas de coordenação vertical e horizontal entre departamentos locais da administração pública com instituiçôes de outros níveis de governo; falta de recursos financeiros; ausência de uma estratégia ou política nacional para orientar os governos locais a desenvolver açóes de mitigação e adaptação e o descompasso entre conhecimento gerado pelos centros de pesquisa científica e a necessidade dos gestores públicos tomadores de decisão nas localidades. (MARTINS; FERREIRA, 2010, p. 235). 
Todo esse contexto acaba por resultar em uma realidade na qual as medidas tomadas para a adaptação acabam por ser incipientes frente à emergência climática envolvida na escala local (BARBI, 2014). Posto isso, percebe-se que há um cenário no qual existe um conjunto de dificuldades para a adoção de respostas para os efeitos negativos das mudanças climáticas que só podem vir a ser superados caso haja um enfrentamento condizente com a complexidade da questão.

Ainda que essas dificuldades sejam experienciadas nas diversas conformaçôes locais, os pequenos municípios possuem aspectos agravantes, como o fato de apresentarem capacidade de resposta menor do que os grandes centros urbanos, que em geral possuem uma capacidade institucional, técnica e financeira maior, bem como recebem uma maior atenção dos estados e do Governo Federal (ARAÚJO; DUNDER; ZANIRATO, 2019a; ZANIRATO, 2019). Uma forma de fazer frente a esses desafios é através de uma gestão pública participativa ampla, que siga os preceitos da Governança Ambiental, como será tratado na seção seguinte.

\section{O Conceito de Governança Ambiental e sua Aplicação no Contexto do Enfrentamento às Mudanças Climáticas}

O conceito de governança que norteia a pesquisa é o da Governança Ambiental. A governança ambiental pode ser definida como

[...] o conjunto de práticas envolvendo instituiçôes e interfaces de atores e interesses, voltados à conservação da qualidade do ambiente natural e construído, em sintonia com os princípios da sustentabilidade. Envolve regras estabelecidas (escritas ou não) e esferas políticas mais amplas do que as estruturas de governo. Em sociedades complexas, governança envolve, geralmente, um complexo jogo de pressôes e representaçôes, onde os governos são (ou devem ser) parte ativa, mas outras forças se expressam, como os movimentos sociais, lobbies organizados, setores econômicos, opinião pública, etc. (BURSZTYN; BURSZTYN, 2012, p. 166).

A governança ambiental atua no escopo dos problemas socioambientais tendo como objetivo o alcance de uma maior sustentabilidade nas relaçóes sociedade-natureza. Para uma governança ambiental mais efetiva, ela deve privilegiar no rol dos atores envolvidos aqueles que representam a participação social, uma vez que a sociedade é em geral a mais atingida por problemas socioambientais, 
possuindo dessa forma um interesse direto na resolução dos mesmos. Além disso, a sociedade também é a que possui maior capacidade de trazer informaçóes relevantes sobre problemáticas socioambientais no processo de aprendizagem mútua acerca de como encarar os problemas. Nesse sentido, Jacobi e Sinisgalli (2012) afirmam que a governança ambiental

[...] está relacionada com a implementação socialmente aceitável de políticas públicas, um termo mais inclusivo que governo, por abranger a relação Sociedade, Estado, mercados, direito, instituições, políticas e ações governamentais, associadas à qualidade de vida bem estar, notadamente os aspectos relacionados com a saúde ambiental. Isto implica no estabelecimento de um sistema de regras, normas e condutas que reflitam os valores e visões de mundo daqueles indivíduos sujeitos a esse marco normativo. A construção desse sistema é um processo participativo, e acima de tudo, de aprendizagem (JACOBI; SINISGALLI, 2012, p. 1471).

Dentre esses problemas socioambientais está o das mudanças climáticas, onde a governança ambiental é vista como um processo para construção de respostas para a crise climática que parte da constatação de que os efeitos negativos dessa crise, como os desastres decorrentes de EHEs que acometem principalmente as populaçóes mais vulneráveis, “[...] não podem ser vistos como fatalidades, mas na maioria dos casos podem ser previstos e evitados" (JACOBI; SULAIMAN, 2016, p. 134).

Trata-se assim de um conceito que possui a capacidade de contribuir para a resolução de problemas socioambientais complexos como as mudanças climáticas (JACOBI; SULAIMAN, 2016; GORDON, 2018; PATTERSON; HUITEMA, 2019), que precisam da cooperação entre diversos campos do conhecimento para a reflexão sobre a temática e da atuação de profissionais das diferentes áreas do conhecimento para a proposição de açóes para a sua resolução, tanto na perspectiva da mitigação quanto da adaptaçáo.

No que diz respeito à adaptação aos efeitos negativos das mudanças climáticas, o poder público possui um papel de grande relevância no estímulo da adoção de medidas adaptativas no espaço da localidade. Para que isso ocorra, é necessário que o poder público trabalhe com a perspectiva de uma atuação preventiva e participativa, pautando-se por uma governança ambiental dos riscos de desastres. Isso por sua vez levará ao desenvolvimento de uma capacidade adaptativa condizente com uma gestão baseada na prevenção e na justiça social (JACOBI; SULAIMAN, 2016). 
Ainda que o foco das discussóes acerca da questão climática se dê no âmbito da relação entre países, as cidades vêm tomando um papel de destaque cada vez maior na discussão sobre a governança global das mudanças climáticas (GORDON, 2018). Entretanto, o conhecimento gerado sobre o que é uma governança efetiva do clima urbano ainda é considerado fragmentado e disperso, além do fato de que muitas cidades ao redor do mundo não estáo tomando as medidas necessárias para a adaptação às mudanças climáticas (VAN DER HEIJDEN, 2019).

A adaptação aos efeitos das mudanças climáticas dentro da perspectiva da governança ambiental também deve partir do entendimento de que a questáo climática como um todo é caracterizada por ser multifacetada, necessitando consequentemente de uma tomada de decisão que envolva uma gama ampliada de atores (JACOBI et al., 2019). Essa tomada de decisão deve então advir de espaços de participaçáo que sejam efetivamente públicos, o que demanda uma disposição por parte do poder público em criar espaços públicos e plurais de articulação e participação (JACOBI et al., 2019).

A compreensão da questão socioambiental atrelada ao processo de mudanças climáticas e a própria incorporação de uma governança ambiental efetiva, são grandes desafios que tendem a se exacerbar no contexto de pequenos municípios. Dessa forma, pretende-se verificar por meio de um estudo de caso como esses desafios se materializam e verificar também como esses desafios podem ser enfrentados no contexto específico de pequenas localidades, considerando inclusive as relaçóes que essas localidades possuem com outras conformaçôes territoriais como a Macrometrópole Paulista, visualizando-se essa relação através de uma perspectiva de governança multinível e contribuindo assim para a construção de um ambiente propício para a colaboração e movimentação do capital social da sociedade para o enfrentamento das mudanças climáticas por meio de práticas de governança mais inclusivas, amplas e democráticas (FREY, 2019).

\section{Estudo de caso: Governança Ambiental e Adaptação às Mudanças Climáticas nos Pequenos Municípios do Vale Histórico Paulista}

Os municípios de Arapeí, Areias e São José do Barreiro se localizam no Estado de São Paulo, na região comumente chamada de Vale Histórico Paulista (Figura 1). Esses municípios apresentam características históricas e socioeconômicas semelhantes, que em última análise acarretam em dificuldades para o enfrentamento dos problemas socioambientais associados às mudanças climáticas (ARAÚJO; DUNDER; ZANIRATO, 2019b). 
Figura 1 - Mapa de localização dos municípios de Arapeí, Areias e São José do Barreiro dentro da delimitação da Macrometrópole Paulista, no Estado de Sáo Paulo

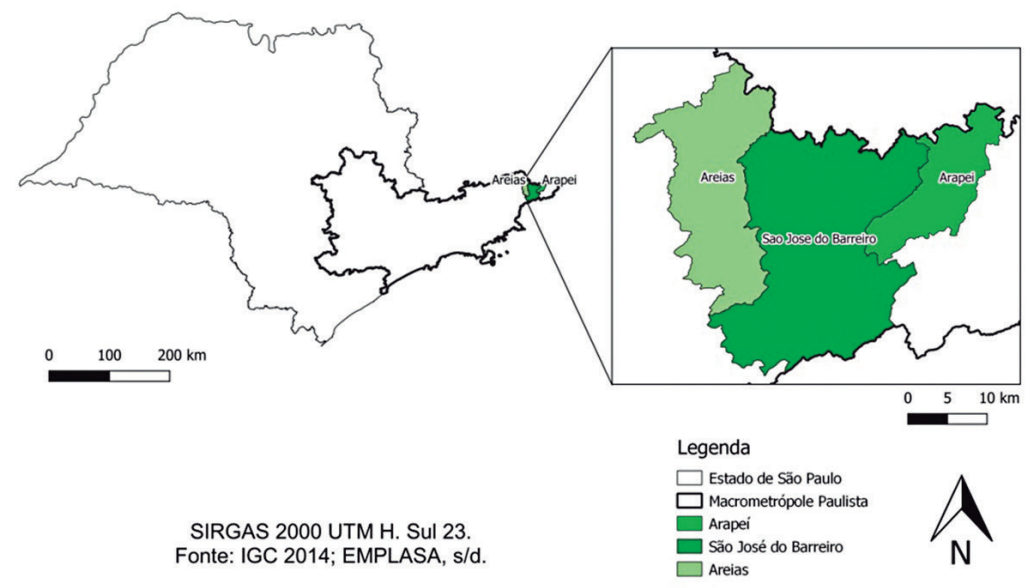

Fonte: Elaboração própria.

Dentre as características dos municípios, destaca-se: o tamanho populacional, cujo montante de cada um é inferior a cinco mil habitantes, sendo que municípios como Arapeí e São José do Barreiro sofrem inclusive com perda de contingente populacional; relevante presença de áreas rurais; e indicadores sociais como o Îndice Paulista de Vulnerabilidade Social (IPVS), que classifica a vulnerabilidade dos munícipios como "muito alto" e o índice Paulista de Responsabilidade Social (IPRS), que classifica Areias e São José do Barreiro como "vulneráveis", estando apenas Arapeí na condição de "em transição" (SEADE, 2010, 2020), como exposto nas tabelas a seguir.

Tabela 1 - Informaçóes Populacionais de Arapeí, SP

\begin{tabular}{|c|c|}
\hline \multicolumn{2}{|l|}{ Município de Arapeí - SP } \\
\hline População - 2019 & 2.472 \\
\hline Taxa Geométrica de Crescimento Anual da população (Em \% a.a.) - 2019 & $-0,10$ \\
\hline Grau de Urbanização (Em \%) - 2019 & 77,43 \\
\hline IPRS - Grupo em 2018 & Em Transição \\
\hline IPVS - 2010 & Muito Alto \\
\hline
\end{tabular}

Fonte: SEADE (2020). 
Tabela 2 - Informaçóes Populacionais de Areias, SP

\begin{tabular}{|l|l|}
\hline Município de Areias - SP & \\
\hline População - 2019 & 3.825 \\
\hline Taxa Geométrica de Crescimento Anual da população (Em \% a.a.) - 2019 & 0,38 \\
\hline Grau de Urbanização (Em \%) - 2019 & 67,03 \\
\hline IPRS - Grupo em 2018 & Vulneráveis \\
\hline IPVS - 2010 & Muito Alto \\
\hline
\end{tabular}

Fonte: SEADE (2020).

Tabela 3 - Informações Populacionais de São José do Barreiro, SP

\begin{tabular}{|l|l|}
\hline \multicolumn{2}{|l|}{ Município de São José do Barreiro - SP } \\
\hline População - 2019 & 4.069 \\
\hline Taxa Geométrica de Crescimento Anual da população (Em \% a.a.) - 2019 & $-0,02$ \\
\hline Grau de Urbanização (Em \%) - 2019 & 78,27 \\
\hline IPRS - Grupo em 2018 & Vulneráveis \\
\hline IPVS - 2010 & Muito Alto \\
\hline
\end{tabular}

Fonte: SEADE (2020).

O processo de urbanização nos municípios é caracterizado como de dinâmica lenta, mantendo boa parte das edificaçóes dos séculos XIX e início de $\mathrm{XX}$. Essas construçóes empregaram técnicas construtivas (taipa de pilão, pau a pique e adobe) e materiais (argila e madeira) que são vulneráveis aos efeitos das mudanças climáticas, com destaque para o aumento da umidade (ZANIRATO et al., 2014; ZANIRATO, 2016).

A regiáo onde os municípios se inserem também apresenta um importante histórico de transformaçôes relacionado ao uso e ocupação do território que impactam até os dias atuais os recursos hídricos, como a devastação da vegetação nativa, que expóe o solo a processos erosivos para a cultura extensiva do café a partir do século XVIII, e a posterior conversão dessas áreas (com o fim da economia cafeeira) para áreas de pastagens e silvicultura. Esses impactos incidem diretamente na segurança hídrica local, tornando os municípios mais frágeis às mudanças climáticas e seus efeitos relacionados à água (DUNDER; ZANIRATO, 2019; ARAÚJO; DUNDER, 2021).

Também é apresentado um histórico de desastres desencadeados por EHEs, como escorregamentos (entre 2000 a 2011, Areias e Arapeí tiveram a de 
1 a 5 eventos de escorregamentos e São Jose do Barreiro de 6 a 10 escorregamentos) e inundaçóes em pontos críticos, que tendem a aumentar em frequência e intensidade com as mudanças climáticas se nada for feito. O VHP se localiza entre a depressão do Rio Paraíba do Sul e as escarpas da Serra da Bocaina, tendo assim um relevo bastante acidentado que favorece a ocorrência de escorregamentos. Além disso, os municípios estudados apresentam rios perpassando seu perímetro urbano, o que aumenta a suscetibilidade a inundaçóes em suas áreas urbanas (ARAÚJO; DUNDER; ZANIRATO, 2019b).

Frente a este cenário, o presente estudo de caso se concentra na análise da capacidade institucional que os pequenos municípios em questáo possuem para enfrentar os efeitos do processo de MCG, partindo-se da análise de conteúdo de políticas e planos presentes nas localidades e do fato de estudos anteriores já terem cenários modelados para a região (ZANIRATO et al., 2014; ZANIRATO, 2016).

Análises preliminares realizadas em planos como o Plano de Saneamento Básico dos municípios (PLANSAN, 2013a, 2013b, 2013c) permitem verificar que a temática das mudanças climáticas está presente de forma marginal na normativa urbana dos municípios, uma vez que náo é citada de forma direta nos planos analisados, a despeito de existirem ações que podem vir a contribuir para a adaptação e existirem diagnósticos que tratam sobre problemas que tendem a se exacerbar com as mudanças climáticas. Destaca-se no escopo da análise preliminar a abordagem de questóes como a necessidade de expansão e garantia do abastecimento de água para os munícipes, a necessidade de expansão da coleta e tratamento de esgoto, que não é universalizada e impacta negativamente nos recursos hídricos, e a importância da drenagem e da microdrenagem principalmente nos espaços urbanos, uma reconhecida deficiência das localidades que aumenta os riscos relacionados a cheias e enchentes.

A adoção de respostas para eventos extremos já experienciados tem esbarrado em dificuldades técnicas e financeiras reconhecidas pelos gestores públicos em algumas das entrevistas realizadas, que apontam para a adoçáo de medidas pontuais para enfrentar problemas recorrentes e a necessidade de se colocar em prática açóes já presentes nos planos.

Isso pode ser visto, por exemplo, na fala do gestor público de Areias, que afirmou que a principal dificuldade é de ordem financeira, que faz com que ações preventivas como a adoção de medidas de engenharia para evitar construção em áreas de risco esbarrem no custo.

Esse fato, somado à dificuldade expressada nas entrevistas de se visualizar as questôes relacionadas às mudanças climáticas como um problema também 
local, acaba por dificultar a adaptação no contexto dos pequenos municípios. A exemplo disso, o gestor público de Arapeí trouxe na entrevista realizada sua percepção de que as mudanças climáticas são um problema global e que, embora impacte todos os territórios, é um problema mais específico de grandes centros urbanos, não sendo uma grande preocupação para o município por se tratar de uma localidade com grandes Unidades de Conservação. Nessa mesma toada, o gestor público de Areias afirmou não ter muitos problemas de ordem ambiental (o que inclui as mudanças climáticas) por ter a Serra da Bocaína muito bem preservada na extensão do município e o desenvolvimento da área urbana buscar respeitar as leis ambientais. O gestor público de São José do Barreiro foi o que mais se aproximou da compreensão da ocorrência de EHEs na localidade, posto que o município se encontra em uma regiáo montanhosa onde ocorrem deslizamentos de terra.

A questão da participação social na discussão, elaboração e implementação de políticas públicas e na tomada de açóes para a prevenção de problemas relacionados às mudanças climáticas e a respostas a desastres também foram tratadas nas entrevistas. De acordo com a resposta dos gestores públicos dos municípios em estudo, a participação esbarra em dificuldades técnicas e culturais, embora seja reconhecida como um aspecto importante. Assim, pode-se encarar que se trata de um campo emergente para a apreensão da governança ambiental em prol da adoção de medidas adaptativas às mudanças climáticas, ainda não devidamente exploradas institucionalmente.

\section{Conclusão}

A mudança climática é um fenômeno que já está ocorrendo e que já apresenta efeitos negativos em todo o planeta, o que inclui as sociedades humanas. Esses efeitos são distribuídos de forma desigual e tendem a se materializar principalmente na escala da localidade.

Os impactos decorrentes dessa distribuição desigual tem a característica de atingir principalmente os estratos populacionais mais vulneráveis. Além disso, a desigualdade também se espelha no contexto das conformaçôes territoriais, posto que em geral pequenos municípios apresentam uma capacidade de resposta menor do que a dos grandes centros urbanos, que possuem maior capacidade técnica e financeira para se preparar para um cenário de maior frequência e intensidade de eventos extremos.

Com este entendimento, o estudo de caso que se dá no escopo de uma pesquisa de nível de mestrado acadêmico está buscando verificar a capacidade 
institucional de pequenos municípios da Macrometrópole Paulista (com especial atenção para os localizados na regiáo do VHP) para a adaptação aos efeitos das mudanças climáticas, o que inclui a ocorrência de desastres relacionados aos EHEs, uma tipologia de desastre que já ocorre nos municípios estudados por conta da região onde estes se inserem ser geograficamente suscetível.

A revisão bibliográfica acerca do conceito de governança ambiental, tido como um conceito norteador para a reflexão sobre o tema da adaptação às mudanças climáticas na escala local permitiu verificar que este conceito tem a capacidade de contribuir para o enfrentamento de uma problemática complexa como as mudanças climáticas, estimulando uma maior participação da sociedade civil nas decisóes de âmbito governamental e tornando as políticas públicas que podem atuar na adaptação às mudanças climáticas mais efetivas.

Até o momento, por se tratar de uma pesquisa ainda em andamento, é possível concluir que uma governança ambiental para a construçáo da adaptação às mudanças climáticas de forma que essa seja pautada por uma maior participação da sociedade civil é questão desafiadora principalmente no âmbito de pequenos municípios, que carecem de maior aparato técnico, institucional, socioeconômico e de uma maior cultura participativa por parte dos munícipes.

Essa conclusão é subsidiada pelos resultados parciais obtidos por meio de: entrevistas realizadas com os gestores públicos dos municípios, que indicaram a dificuldade técnica e financeira da gestão local e a baixa participação social para tratar de problemas socioambientais relacionados com as mudanças climáticas nos três municípios estudados; e pelos indicadores socioeconômicos dos municípios.

Além disso, pode-se concluir que os municípios em estudo apresentam dificuldades institucionais no que concerne à sua normativa urbana para enfrentar as mudanças climáticas, posto que o tema não aparece em planos importantes como os Planos Integrados de Saneamento Básico, embora estes tratem de problemas relacionados indiretamente com EHEs.

Nesse sentido, um maior conhecimento acerca do constructo teórico que envolve o conceito de governança ambiental, bem como a análise da capacidade institucional dos municípios, irá contribuir para uma melhor compreensão acerca da adaptação às mudanças climáticas em pequenos municípios, que como visto, possuem dificuldades inerentes que tornam o cenário de emergência climática ainda maior. 


\section{REFERÊNCIAS}

ANDERSON, K. Duality in climate Science. Nature Geoscience, London, v. 8, p. 898-900, 2015.

ARAÚJO, G. P.; DUNDER, B. D. Segurança hídrica de pequenos municípios em um contexto de emergência climática: compreensão para a adaptação. In: TEIXEIRA, R. L. P. (org.). Problemas socioambientais emergentes: contribuições teóricas e práticas. Bauru, SP: Gradus, 2021. p. 41-52.

ARAÚJO, G. P.; DUNDER, B. D.; ZANIRATO, S. H. Medidas Adaptativas para Pequenos Municípios num Cenário de Variabilidade Climática: Desafios da Gestão Local. In: ENANPEGE, 13., 2019, São Paulo. Anais [...], São Paulo, 2019a. p. 1-13.

ARAÚJO, G. P.; DUNDER, B. D.; ZANIRATO, S. H. Processo de Produção do Espaço no Vale Histórico Paulista e a Adaptação aos Efeitos das Mudanças Climáticas Globais: Fragilidades e Potencialidades. In: ENCONTRO NACIONAL DA ANPPAS, 9., 2019, Brasília. Anais [...], Brasília, 2019b. p. 2724-2742.

BARBI, F. Governando as Mudanças Climáticas no Nível Local: Riscos e Respostas Políticas. 2014. 250 p. Tese (Doutorado em Ambiente e Sociedade) - Universidade Estadual de Campinas, Campinas, 2014.

BARDIN. L. Análise de conteúdo. Lisboa: Ediçōes 70, 1977.

BATHIANY, S. et al. Climate models predict increasing temperature variability in poor countries. Science Advances, Washington, v. 4, n. 5, 2018.

BONI, V.; QUARESMA, S. Aprendendo a entrevistar: como fazer entrevistas em Ciências Sociais. Em Tese, Belo Horizonte, v. 2, n. 3, p. 68-80, 2005.

BURSZTYN, M.; BURSZTYN, M. A. Fundamentos de Política e Gestáo Ambiental: Os Caminhos do Desenvolvimento Sustentável. Rio de Janeiro: Garamond, 2012.

DUNDER, B. D.; ZANIRATO, S. H. Transformações no Uso e Ocupação do Solo no Vale Histórico Paulista e seus Reflexos nos Recursos Hídricos. In: IX ENCONTRO NACIONAL DA ANPPAS, 9., 2019, Brasília. Anais [...], Brasília, 2019. p. 1329-1338.

FERNANDES, P. H. C. O urbano brasileiro a partir das pequenas cidades. Revista Eletrônica Geoaraguaia, Barra das Garças, v. 8, n. 1, p. 13-31, 2018.

FLORES, B. A.; GAUDIANO, É. J. G. Percepción social de los eventos climáticos extremos: una revisión teórica enfocada en la reducción del riesgo. Trayectorias, Monterrey, v. 16, n. 39, p. 36-58, 2014. 
FREY, K. Governança Multinível/Policêntrica e as Políticas Públicas de Mudanças Climáticas. In: JACOBI, P. R.; TRANI, E. (org.). Planejando o Futuro Hoje: ODS13, Adaptação e Mudanças Climáticas em São Paulo. São Paulo: IEE-USP, 2019. p. 20-23.

GIDDENS, A. A política da mudança climática. Tradução de Vera Ribeiro. Rio de Janeiro: Zahar, 2010. Título original: The Politcs of Climate Change.

GIL, A. C. Como elaborar projetos de pesquisa. 4. ed. Sáo Paulo: Atlas, 2002.

GORDON, D. J. Global urban climate governance in three and a half parts: Experimentation, coordination, integration (and contestation). Wiley Interdisciplinary Reviews: Climate Change, Oxford, v. 9, n. 6, p. e546, 2018.

INTERGOVERNMENTAL PANEL ON CLIMATE CHANGE [IPCC]. Climate Change 2014: Synthesis Report. Contribution of Working Groups I, II and III to the Fifth Assessment Report of the Intergovernmental Panel on Climate Change. Geneva, Switzerland: IPCC, 2014.

JACOBI, P. R. et al. Importância da Sociedade Civil nos Processos Participativos. In: JACOBI, P. R.; TRANI, E. (org.). Planejando o Futuro Hoje: ODS13, Adaptação e Mudanças Climáticas em São Paulo. São Paulo: IEE-USP, 2019. p. 57-61.

JACOBI, P. R.; SINISGALLI, P. A. A. Governança ambiental e economia verde. Ciência \& Saúde Coletiva, Rio de Janeiro, v. 17, n. 6, p. 1469-1478, 2012.

JACOBI, P. R.; SULAIMAN, S. N. Governança ambiental urbana em face das mudanças climáticas. Revista USP, São Paulo, n. 109, p. 133-142, 2016.

KÄSSMAYER, K.; FRAXE NETO, H. J. A entrada em vigor do Acordo de Paris: o que muda para o Brasil? Brasília: Senado Federal, 2016. Disponível em: http:// www2.senado.leg.br/bdsf/bitstream/handle/id/528873/Textos_para_discussao_215. pdf?sequence=1. Acesso em: 31 maio 2021.

LANDA, R.; MAGAÑA, V.; NERI, C. Agua y clima: elementos para la adaptación al cambio climático. Cidade do México: Semarnat, 2008.

LAVELL, A. La gestión local del riesgo: nociones y precisiones al concepto y la práctica. Guatemala: CEPREDENAC, 2003. Disponível em: http://www.disasterinfo.net/lideres/portugues/brasil\%2006/Material\%20previo/Allangestriesg.pdf. Acesso em: 26 dez. 2019.

LONDE, L. R. et al. Desastres relacionados à água no Brasil: perspectivas e recomendaçóes. Ambiente \& Sociedade, Campinas, v. 17, n. 4, p. 133-152, 2014. 
MARTINS, R. D.; FERREIRA, L. C. Uma revisão crítica sobre cidades e mudança climática: vinho velho em garrafa nova ou um novo paradigma de ação para a governança local?. Revista de Administraçáo Pública, Rio de Janeiro, v. 45, n. 3, p. 611-641, maio/jun. 2011.

MARTINS, R. D.; FERREIRA, L. C. Oportunidades e barreiras para políticas locais e subnacionais de enfrentamentos das mudanças climáticas em áreas urbanas: evidências de diferentes contextos. Ambiente \& Sociedade, Campinas, v. XIII, n. 2, p. 223-242, jul./dez. 2010.

NETO, P. D. T. Ecopolítica das mudanças climáticas: o IPCC e o ecologismo dos pobres. Rio de Janeiro: Centro Edelstein de Pesquisas Sociais, 2010. E-book.

NOGUEIRA, F. R.; OLIVEIRA, V. E.; CANIL, K. Políticas Públicas Regionais para Gestão de Riscos: O processo de Implementação no ABC, SP. Ambiente \& Sociedade, Campinas, v. XVII, n. 4, p. 177-194, out./dez. 2014.

NUNES, L. H. Mudanças climáticas, extremos atmosféricos e padrôes de risco a desastres hidrometeorológicos. In: HOGAN, D. J.; MARANDOLA JR. E. (org.). Populaçáo e mudança climática: dimensôes humanas das mudanças ambientais globais. Campinas: Núcleo de Estudos de População-Nepo/Unicamp; Brasília: UNFPA, 2009a. p. 53-73.

NUNES, L. H. Compreensóes e açóes frente aos padróes espaciais e temporais de riscos e desastres. Territorium, Coimbra, n. 16, p. 179-189, 2009 b.

PATTERSON, J. J.; HUITEMA, D. Institutional innovation in urban governance: The case of climate change adaptation. Journal of Environmental Planning and Management, Abingdon, v. 62, n. 3, p. 374-398, 2019.

PLANSAN. Plano municipal integrado de saneamento básico. Arapeí, 2013a. Disponível em: https://smastr16.blob.core.windows.net/conesan/sites/253/2020/10/ arapei_ae_du_rs_2011.pdf. Acesso em: 21 Jan. 2021.

PLANSAN. Plano municipal integrado de saneamento básico. Areais, 2013b. Disponível em: https://smastr20.blob.core.windows.net/conesan/Areias_AE_DU_ RS_2011.pdf. Acesso em: 21 Jan. 2021.

PLANSAN. Plano municipal integrado de saneamento básico. Sáo José do Barreiro, 2013c. Disponível em: https://smastr20.blob.core.windows.net/conesan/ Sao\%20Jose\%20do\%20Barreiro_AE_DU_RS_2011.pdf. Acesso em: 21 Jan. 2021.

ROCKSTRÖM, J. et al. A safe operating space for humanity. Nature, London, v. 461, p. 472-475, 2009. 
SISTEMA ESTADUAL DE ANÁLISE DE DADOS [SEADE]. Perfil dos municípios paulistas. 2020. Disponível em: http://perfil.seade.gov.br/. Acesso em: 21 jan. 2020.

SISTEMA ESTADUAL DE ANÁLISE DE DADOS [SEADE]. Índice Paulista de Vulnerabilidade Social. São Paulo: SEADE, 2010. Disponível em: http://ipvs.seade. gov.br/view/pdf/ipvs/principais_resultados.pdf. Acesso em: 21 jan. 2022.

STEFFEN, W. et al. Trajectories of the Earth System in the Anthropocene. Proceedings of the National Academy of Sciences, Washington, v. 115, n. 33, p. 8252-8259, 2018.

STEFFEN, W. et al. Planetary boundaries: Guiding human development on a changing planet. Science, Washington, v. 347, n. 6223, p. 1259855, 2015.

TORRES, P. H. C. et al. Efecto Nueva Zembla y Justicia Climática en Brasil: adaptación sin justicia no es adaptación, es espejismo. Terra: Nueva Etapa, Caracas, v. 34, n. 59, 2020.

VAN DER HEIJDEN, J. Studying urban climate governance: where to begin, what to look for, and how to make a meaningful contribution to scholarship and practice. Earth System Governance, Amsterdam, p. 100005, 2019.

VARGAS, M. C. Águas revoltas: riscos. Vulnerabilidade e adaptação à mudança climática global na gestão dos recursos hídricos e do saneamento. Por uma política climática metropolitana na Baixada Santista. In: OJIMA, R.; MARANDOLA JR., E. (org.). Mudanças climáticas e as cidades: novos e antigos debates na busca da sustentabilidade urbana e social. São Paulo: Blucher, 2013. p. 75-89.

VICTOR, D. G. et al. Prove Paris was more than paper promises. Nature, London, v. 548, p. 25-27, 2017.

YIN, R. K. Estudo de Caso: Planejamento e métodos. 3. ed. Porto Alegre: Bookman, 2005.

ZANIRATO, S. H. O papel das pequenas cidades da Macrometrópole Paulista no cenário de variabilidade climática. Diálogos socioambientais na Macrometrópole Paulista, São Bernardo do Campo, v. 4, n. 4, p. 16-18, 2019.

ZANIRATO, S. H. Estratégias de adaptaçáo para as vulnerabilidades do patrimônio cultural edificado dos municípios do Vale Histórico Paulista. 2016. 265 p. Tese (Livre Docência) - Escola de Artes, Ciências e Humanidades, Universidade de São Paulo, São Paulo, 2016. 
ZANIRATO, S. H. et al. Patrimônio cultural do Vale Histórico Paulista: análise da vulnerabilidade às mudanças climáticas. São Paulo: Pesquisa FAPESP/ CONDEPHAAT, 2014.

Recebido em: 30 de março de 2021

Aprovado em: 16 de setembro de 2021 